\title{
MORPHOMETRIC STUDY OF PTERION AND ITS CLINICAL SIGNIFICANCE
}

\author{
GYANARANJAN NAYAK*, BISWA BHUSAN MOHANTY, SAURJYA RANJAN DAS
}

Department of Anatomy, IMS and SUM Hospital, SOA University, Bhubaneswar - 751 003, 0disha, India. Email: drgrn82@gmail.com

Received: 13 April 2017, Revised and Accepted: 17 June 2017

\section{ABSTRACT}

Objective: Pterion is an area formed by the union of frontal, parietal, temporal, and sphenoid bones. It exhibits variations in the sutural pattern of fusion of constituent bones. Basing on this, the pterion can be classified into four varieties. According to Murphy, these are sphenoparietal, frontotemporal, stellate, and epipteric. The anatomical location of the pterion is necessary for the surgical management of extradural hemorrhage, aneurysm, and brain tumors located in the anterior and middle cranial fossae.The purpose of this study is to find out the prevalence of different varieties of pterion and determine the position of pterion using anatomical landmarks.

Methods: The present study included fifty skulls of unknown age and sex. The skulls were studied macroscopically for the anatomical variations of pterion. The distance between the center of the pterion to the midpoint of zygomatic arch and pterion to the frontozygomatic suture was measured using Vernier calipers.

Results: The sphenoparietal variety was the most common variety of pterion found in the study followed by the epipteric variety and the stellate variety, respectively. The distance between pterion and back of the frontozygomatic suture was found to be $3.48 \pm 0.21 \mathrm{~cm}$ on the right side and $3.41 \pm$ $0.16 \mathrm{~cm}$ on the left side. The distance between pterion and the midpoint of upper border of the zygomatic arch was found to be $4.01 \pm 0.19 \mathrm{~cm}$ on the right side and $3.94 \pm 0.2 \mathrm{~cm}$ on the left side.

Conclusion: The findings will be helpful for radiologists and neurosurgeons.

Keywords: Pterion, Midpoint of zygomatic arch, Frontozygomatic suture.

(C) 2017 The Authors. Published by Innovare Academic Sciences Pvt Ltd. This is an open access article under the CC BY license (http://creativecommons. org/licenses/by/4. 0/) DOI: http://dx.doi.org/10.22159/ajpcr.2017.v10i10.19138

\section{INTRODUCTION}

Pterion represents the junction of frontal, sphenoid, parietal, and temporal bones in the temporal fossa. It is situated within $1 \mathrm{~cm}$ diameter of a circle centered approximately $2.6 \mathrm{~cm}$ posterior and $1.3 \mathrm{~cm}$ superior to the posterolateral margin of the frontozygomatic suture. Alternatively, the pterion is located approximately $4 \mathrm{~cm}$ above the midpoint of upper border of the zygomatic arch [1]. Pterion usually marks the position of the anterior (frontal) branch of the middle meningeal artery, lateral sulcus of brain and Broca's motor speech area [1]. Knowledge of the location of the middle meningeal artery is important for the accurate position of the burr holes to evacuate extradural hematoma caused due to injury to middle meningeal vessels [1]. Pterion is also a primary site in surgeries to gain access to sphenoid ridge and optic canal [2]. Hence, the location of the pterion is very important in neurosurgery.

The pterion corresponds to the site of anterolateral fontanelle of the neonatal skull, which closes at 3 months of age [1]. The fontanelles provide for the molding of the fetal head during its passage through the birth canal as well as the rapid growth of the brain during infancy.

The pterion exhibits variations in the sutural pattern of fusion of constituent bones. Basing on this, the pterion can be classified into various types. According to Murphy [3], these are - sphenoparietal, frontotemporal, stellate, and epipteric. In sphenoparietal variety, sphenoid and parietal bones are in direct contact. Frontotemporal type is a sutural pattern in which the frontal and temporal bones are in direct contact. In stellate type, all four contributing bones such as frontal, parietal, sphenoid, and temporal bones articulate at a point. The fourth one is the epipteric type, which has the presence of small sutural bones between sphenoid and parietal bones. These variations are important for anthropologists.
As pterion is an important neurosurgical landmark and it exhibits variations in its sutural pattern, the present study was conducted to define the types of pterion and map its location.

\section{METHODS}

The present study included fifty dry, human skulls of unknown age and sex available in the Museum of Department of Anatomy of a Medical College at Bhubaneswar. Skulls exhibiting pathological changes and congenital anomalies were excluded from the study. Broken skulls and skulls with obliterated sutures due to synostosis were also excluded from the study. The skulls were studied macroscopically to find the sutural pattern of the pterion on both the sides.

For locating the pterion the smallest circle involving the four contributing bones was drawn. The center of the circle was taken as the center of the pterion $[4,5]$. Two linear measurements were taken on the external aspect of the skull from the center of the pterion to determine its location. One measurement was taken vertically from the center of the pterion to the posterolateral aspect of frontozygomatic suture (PFZS), and the other was from the center of the pterion to the midpoint of upper border of the zygomatic arch.

The measurements were taken on both sides of the skull with a digital Vernier caliper. The measurements were taken twice, and then the average was calculated to minimize bias error. All the data obtained were tabulated and analyzed using Microsoft Excel software.

\section{RESULTS}

In the present study, three types of sutural patterns of pterion were observed. Sphenoparietal variety (Fig. 1) was the most common variety. 
The frequency was $40(80 \%)$ on the right side and $45(90 \%)$ on the left side. The second most common variety was epipteric type (Fig. 2). The frequency was $7(14 \%)$ on the right side and $3(6 \%)$ on the left side. Stellate type of pterion (Fig. 3) was observed in $3(6 \%)$ cases on the right side and $2(4 \%)$ case on the left side. This was the third most common variety. No skulls exhibited the frontotemporal type of pterion in the study. The frequency of different types of pterion after combining both the sides is depicted in Table 1.

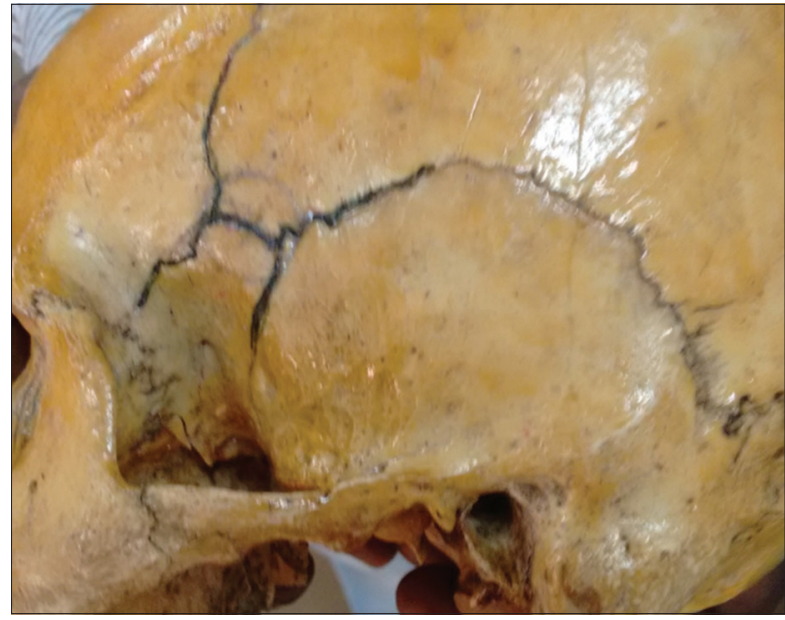

Fig. 1: Sphenoparietal variety of pterion

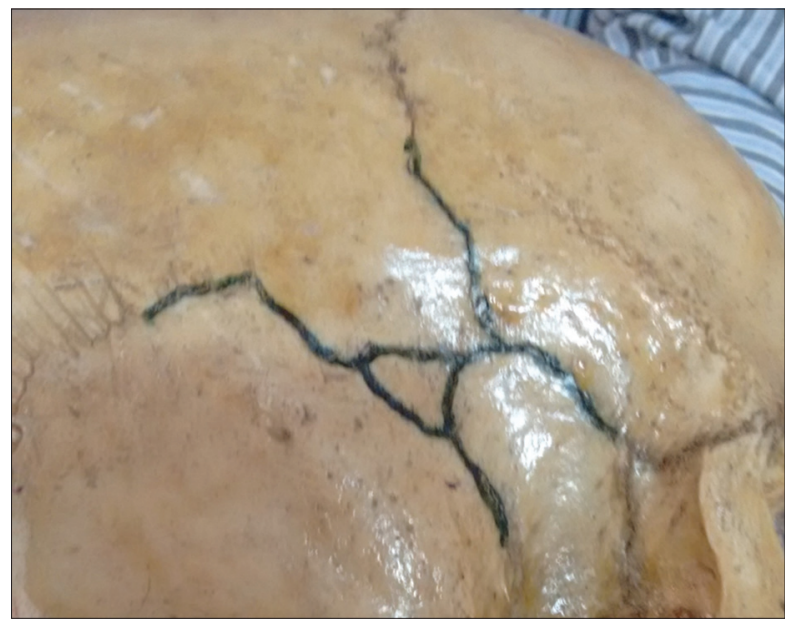

Fig. 2: Epipteric variety of pterion

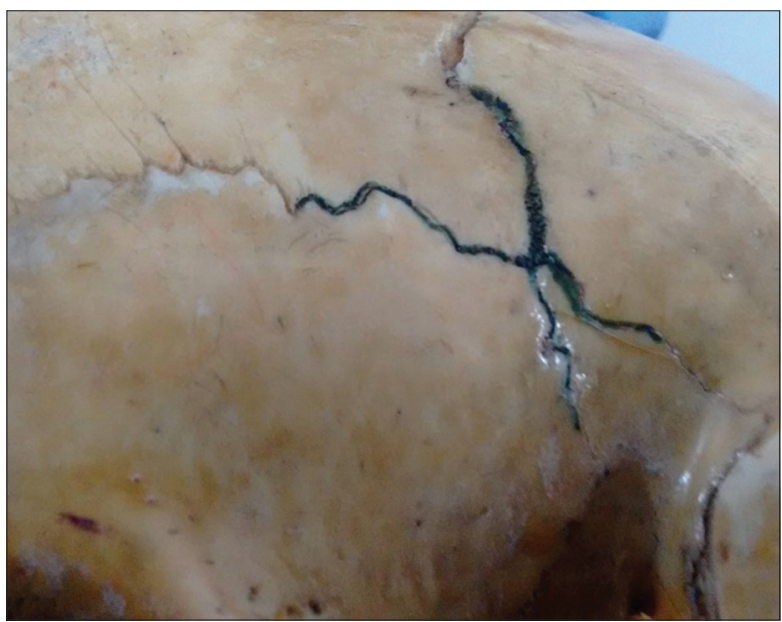

Fig. 3: Stellate variety of pterion
The distance between the midpoint of pterion and the posterolateral aspect of frontozygomatic suture was found to be $3.48 \pm 0.21 \mathrm{~cm}$ on the right side and $3.41 \pm 0.16 \mathrm{~cm}$ on the left side. The distance between the center of pterion to the midpoint of upper border of zygomatic arch was found to be $4.01 \pm 0.19 \mathrm{~cm}$ on the right side and $3.94 \pm 0.2 \mathrm{~cm}$ on the left side. The distances were higher on the right side than the left side. However, the difference was not found to be statistically significant (unpaired t-test was applied and $\mathrm{p}<0.5$ ). Combining both the sides, the center of the pterion was found to be located at a distance of $3.46 \pm$ $0.2 \mathrm{~cm}$ from the posterolateral aspect of frontozygomatic suture and at a distance of $3.98 \pm 0.2 \mathrm{~cm}$ from the midpoint of upper border of zygomatic arch. The distances measured are represented in Table 2 .

\section{DISCUSSION}

In neurosurgery, it is important to approach through the most suitable bony aperture to be minimally invasive [6]. Pterional access either alone or in combination with other approaches has come up as a minimally invasive approach for a wide variety of neurosurgical disorders. Hence, the knowledge of the peculiar morphology of pterion is necessary for the pterional approach used in neurosurgery [7].

The present study observed that the most common type of pterion was sphenoparietal (85\%) followed by epipteric (15\%) and stellate (5\%), respectively.

This is similar to the findings of studies by Murphy [3], Matsumura et al. [8], Lee et al. [9], Eboh et al. [10], Oguz et al. [11], Katri et al. [12], and Saxena et al. [2].

Murphy [3] reported $73 \%$ sphenoparietal, $18.5 \%$ stellate, $7.5 \%$ frontotemporal, and 1\% epiptric type of pterion in an Australian population. Matsumura et al. [8] in their study in Japan, have reported $79.1 \%$ sphenoparietal, $17.7 \%$ stellate, $2.6 \%$ frontotemporal, and $0.6 \%$ epipteric type of pterion. Lee et al. [9] have reported $76.5 \%$ sphenoparietal and $23.5 \%$ epipteric type of pterions in their study involving Korean population. They could not find any frontotemporal or stellate type in their study. Eboh et al. [10] reported 83\% sphenoparietal, $6 \%$ stellate and $6 \%$ epipteric, $5 \%$ frontotemporal type in their study in Nigeria. Oguz et al. [11] have found 88\% sphenoparietal, 10\% frontotemporal, and $2 \%$ epipteric type in Turkey. They did not find any stellate variety of pterion in their study. In India, Katri et al. [12] have observed $86 \%$ sphenoparietal, $11.7 \%$ epipteric, $2 \%$ frontotemporal, and $0.3 \%$ stellate type of pterion in their study. Another study in India by Saxena et al. [2], has reported $87.7 \%$ sphenoparietal, 16\% frontotemporal, and $2.3 \%$ stellate type of pterion. They have found no epipteric variety in their study.

The present study has revealed the distance between the center of pterion and posterolateral aspect of frontozygomatic suture to be

Table 1: Frequency of different types of pterion in the present study

\begin{tabular}{ll}
\hline Type of pterion & Frequency (\%) \\
\hline Sphenoparietal & $85(85)$ \\
Epipteric & $10(10)$ \\
Stellate & $5(5)$ \\
\hline
\end{tabular}

Table 2: Distance of pterion from various bony landmark

\begin{tabular}{lll}
\hline Side of skull & Parameter & Mean \pm SD (cm) \\
\hline Right & PFZS & $3.48 \pm 0.21$ \\
Right & PMZA & $4.01 \pm 0.19$ \\
Left & PFZS & $3.41 \pm 0.16$ \\
Left & PMZA & $3.94 \pm 0.20$ \\
\hline
\end{tabular}

SD: Standard deviation, PFZS: Pterion to the posterolateral aspect of

frontozygomatic suture, PMZA: Pterion to the midpoint of upper border of the zygomatic arch 
$3.48 \pm 0.21 \mathrm{~cm}$ on the right side and $3.41 \pm 0.16 \mathrm{~cm}$ on the left side. This is similar to the findings of Zalawadia et al. [4] $(3.73 \pm 0.51 \mathrm{~cm}$ on right side; $3.55 \pm 0.42 \mathrm{~cm}$ on left side); Eboh et al. [10] $(3.2 \pm 0.3 \mathrm{~cm}$ on right side and $3.1 \pm 0.2 \mathrm{~cm}$ on left side); Mwachka et al. [13] (3 \pm $0.3 \mathrm{~cm}$ right side and $3 \pm 0.4 \mathrm{~cm}$ on left side) and Anjana et al. [5] (3 \pm $0.4 \mathrm{~cm}$ on right side and $2.9 \pm 0.2 \mathrm{~cm}$ on left side).

The current study has revealed the distance between the center of pterion and the midpoint of upper border of zygomatic arch to be $4.01 \pm 0.19 \mathrm{~cm}$ on the right side and $3.94 \pm 0.2 \mathrm{~cm}$ on the left side. This is similar to the findings of Eboh et al. [10] ( $4 \pm 0.3 \mathrm{~cm}$ on right side and $3.9 \pm 0.3 \mathrm{~cm}$ on left side); Anjana et al. [5] ( $4 \pm 0.5 \mathrm{~cm}$ on right side and $4 \pm 0.2 \mathrm{~cm}$ on left side); Mwachka et al. [13] (3.9 $\pm 0.3 \mathrm{~cm}$ on right side and $3.8 \pm 0.3 \mathrm{~cm}$ on left side). However, Zalawadia et al. [4] have reported the distance as $3.12 \pm 0.44 \mathrm{~cm}$ on the right side and $2.97 \pm$ $0.33 \mathrm{~cm}$ on the left side.

\section{Significance of sutural patterns of pterion}

The knowledge of the sutural patterns of pterion is important for the following reasons:

(a) In epipteric variety of pterion, burr holes placed over the anterior junction for evacuation of extradural hematoma may cause inadvertent penetration into orbit [6]

(b) The sutural pattern of pterion gives a hint towards the volume of brain. The development of the calvarium is tightly coordinated with the type of brain. This explains the prevalence of frontotemporal pattern of sutures among monkeys who have smaller brains compared to humans with larger brains who have sphenoparietal pattern of suture at pterion [14]

(c) The variation of sutural pattern even finds a probable genetic basis. The gene responsible for the articulation of cranial bones in pterion is MSX 2 (on 5q35.2), a gene of homeobox family involved in cranial suture morphogenesis. Working in mice models, it has been proved that MSX 2 gene may be responsible for pterion type and asymmetry [15]. Mutations of MSX 2 gene has been observed in diseases such as Persistent Parietal Foramen Type 1 and Craniosynostosis Type 2. In Craniosynostosis, there is premature fusion of the cranial sutures. Hence, there seems to be a definite role of MSX 2 gene in cranial suture morphogenesis and hence variations of sutural pattern of pterion.

\section{Significance of location of pterion}

Mapping of pterion finds great application in neurosurgery as pterional access has come up as a minimally invasive approach for a number of procedures such as evacuating extradural hematoma, surgery of olfactory meningioma on undersurface of frontal lobe [16], operations on Broca's motor speech area and clipping the aneurysms of middle cerebral artery and upper basilar complex [17]

The pterion is used as an anterolateral landmark in "Cranial suture closure methodology" for determination of age and sex [18]. Hence, locating the pterion is important in archaeological and forensic specimens.

\section{CONCLUSION}

The most common variety of pterion in the present study was found to be of the sphenoparietal type. The study revealed the distance from the center of pterion to posterolateral aspect of frontozygomatic suture as $3.46 \pm 0.2 \mathrm{~cm}$ and from the center of pterion to the midpoint of upper border of zygomatic arch as $3.98 \pm 0.2 \mathrm{~cm}$. This will be useful to neurosurgeons, radiologists, anthropologists, and forensic scientists.

\section{REFERENCES}

1. Standring S, Gray's Anatomy: The Anatomical Basis of Clinical Practice. $40^{\text {st }}$ ed. London: Elsevier; 2015. p. 409-10.

2. Saxena RC, Bilodi AK, Mane SS, Kumar A. Study of pterion in skulls of Awadh area-in and around Lucknow. Kathmandu Univ Med J (KUMJ) 2003;1(1):32-3.

3. Murphy T. The pterion in the Australian aborigine. Am J Phys Anthropol 1956;14(2):225-44.

4. Zalawadia A, Vadgama J, Ruparelia S, Patel S, Rathod SP, Patel SV. Morphometric study of pterion in dry skulls of Gujarat region. Natl J Integr Res Med 1991;1(4):25-9.

5. Anjana S, Satheesa KS, Bhaskar R, Pai SR. Morphometric study of pterion in adult dry skulls in Dakshina Kannada district, Karnataka state, India. Int J Anat Res 2015;3(4):1603-6.

6. Ersoy M, Evliyaoglu C, Bozkurt MC, Konuskan B, Tekdemir I, Keskil IS. Epipteric bones in the pterion may be a surgical pitfall. Minim Invasive Neurosurg 2003;46(6):363-5

7. Urzì F, Iannello A, Torrisi A, Foti P, Mortellaro NF, Cavallaro M. Morphological variability of pterion in the human skull. Ital J Anat Embryol 2003;108(2):83-117.

8. Matsumura G, Kida K, Ichikawa R, Kodama G. Pterion and epipteric bones in Japanese adults and fetuses, with special reference to their formation and variations. Kaibogaku Zasshi 1991;66(5):462-71.

9. Lee UY, Park DK, Kwon SO, Paik DJ, Han SH. Morphological analysis of pterion in Korea. Korean J Phys Anthropol 2001;14(4):281-9.

10. Eboh DE, Obaroefe M. Morphometric study of pterion in dry human skull bones of Nigerians. Int J Morphol 2014;32(1):208-13.

11. Oguz O, Sanli SG, Bozkir MG, Soames RW. The pterion in Turkish male skulls. Surg Radiol Anat 2004;26(3):220-4.

12. Katri CR, Gupta S, Soni JS. Study of pterion and incidence of epistemic bones in dry human skulls of Gujarat. Natl J Integr Res Med 2012;3(2):57-60

13. Mwachka PM, Hassanali J, Odula P. Sutural morphology of the pterion among adult Kenyans. Braz J Morphol Sci 2009;26(1):4-7.

14. Wang Q, Opperman LA, Havill LM, Carlson DS, Dechow PC. Inheritance of sutural pattern at the pterion in Rhesus monkey skulls. Anat Rec A Discov Mol Cell Evol Biol 2006;288(10):1042-9.

15. Hussain SS, Mavishetter GF, Thomas ST, Prasanna LC, Magi MP. A study of sutural morphology of the pterion and asterion among adult Indian skulls. Biomed Res 2011;22(1):73-5.

16. Spektor S, Valarezo J, Fliss DM, Gil Z, Cohen J, Goldman J, et al. Olfactory groove meningiomas from neurosurgical and ear, nose, and throat perspectives: Approaches, techniques, and outcomes. Neurosurgery 2005;57(4):268-80.

17. Bagé EM, Sola RG, González LR, Caniego JL, Cazón CC. Fusiform aneurysm of the middle cerebral artery. Rev Neurol 2002;34(7):655-8.

18. Lovejoy CO, Meindl RS, Mensforth RP, Barton TJ. Multifactorial determination of skeletal age at death: A method and blind tests of its accuracy. Am J Phys Anthropol 1985;68(1):1-14 